ture as that in Thomas et al.'s cladogram. I conclude that the $12 \mathrm{~S}$ ribosomal RNA data constitute insufficient evidence to determine the phylogenetic relationships among these taxa, and in particular that the data do not exclude the possiblity that the thylacine is an outgroup to the Australian lineages.

Our more formal presentation of the Monte Carlo test and its application to other taxonomic data sets ${ }^{5}$ supports the recent view that, for both animals ${ }^{6}$ and plants', the degree of character convergence and reversal found in molecular data sets matches that of morphological data. This property, together with the large number of phylogenetically uninformative characters found in most molecular data sets, suggests that the apparent wealth of molecular information for phylogenetics is frequently illusory.

Division of Wildlife and Ecology,

DANIEL P. FAITH

CSIRO,

PO Box 84, Lyneham,

ACT 2602,

Australia

Thomas ET AL. RePLY-Faith's randomization test, which is similar to one recently published by Archie ${ }^{x}$, demonstrates the absence of any significant departure from randomness for the $12 \mathrm{~S}$ ribosomal RNA gene sequences taken as a whole. But for testing if particular groups of taxa in a tree are monophyletic or not, the bootstrapping approach is more powerful ${ }^{8}$. For the particular question addressed in our paper ${ }^{1}$, the latter test gives significant support for the thylacine-dasyurid clade. Other portions of the tree, such as the position of the bandicoot Echymipera, are not well supported by the $12 \mathrm{~S}$ ribosomal RNA gene data when tested by bootstrapping.

Furthermore, confidence in the existence of the thylacine-dasyurid clade is enhanced by the quantitative immunological results obtained with albumin ${ }^{9}$ and by the finding that the ratio of transitions to transversions observed in the cytochrome $b$ gene is higher for comparisons of Australian marsupial carnivores with each other and the thylacine than for all comparisons of these marsupials with others $^{1}$. In an attempt to achieve even higher confidence, we intend to obtain more sequences from the thylacine and extant marsupials.

As for Faith's view that molecular traits are not superior to morphological ones for building reliable genealogical trees, we refer readers to the case of the orang utan's position among hominoid primates. Despite more than a century of intensive morphological analysis, no statistically significant support emerged for any of the three following trees, in which: the orang utan is less akin than humans are to Afri- can apes; the orang utan is more akin to humans than African apes are; or the orang utan is more akin than humans are to African apes. ${ }^{10.11}$. Yet studies of DNA reveal 121 traits supporting tree $A, 8$ supporting tree $\mathrm{B}$ and 10 supporting tree $\mathrm{C}-$ a highly significant result ${ }^{11}$. A possible reason for Faith's pessimistic view is that the cases to which he refers are for small proteins whose resolving power is inherently low when used to probe deep branches in genealogical trees.

Department of Genetics,

RICHARD H. THOMAS

University of Nottingham

Nottingham NG7 2UH, UK

ALLAN C. WILSON
Division of Biochemistry and
Molecular Biology,
University of California,
Berkeley,
California 94720, USA

1. Thomas, R.H., Schaffner, W., Wilson, A.C. \& Paabo, S. Nature 340, 465-467 (1989).

2. Farris, J.S. Syst. Zool. 28, 483-519 (1979).

3. Faith, D.P. Cladistics 5, 235-258 (1989).

4. Clemens, W.A., Richardson, B.J. \& Baverstock, P.R. in Fauna of Australia Mammalia (eds Walton, D.W. \& Richardson, B. J.) 527-548 (AGPS, Canberra, 1989).

. Faith, D. P. \& Cranston, P. S. Cladistics (in the press)

6. Wyss, A.R., Novacek, M.J. \& Mckenna, M.C. Molec. Biol Wyss, A.R., Novacek, M.
Evol. 4, 99-116 (1987)

. Syvanen, M., Hartman, H. \& Stevens, P.F. J. molec. Evol. 28, 536-544 (1989)

8. Archie, J.W. Syst. Zool.38, 239-252 (1989).

9. Lowenstein, J.M., Sarich, V.M. \& Richardson, B.J. Nature 291, $409-411$ (1981)

10. Wilson, A.C. Scient. Am. 253(4), 164-173 (1985).

11. Wilson, A.C. et al. in The Hierarchy of Life (eds Fernholm. B. et al.) $407-419$ (Elsevier, Amsterdam, 1989).

\section{Papain and related proteins}

SIR-Recent contributions to Scientific Correspondence $^{i-3}$ have addressed the structural similarity of the $111 \mathrm{~K}$ antigen of the malaria parasite Plasmodium falciparum to cysteine proteinases in the amino-acid sequence region containing Cys 22 and Cys 25 in papain. The fact that Cys 585 of the $111 \mathrm{~K}$ antigen is analogous to Cys 22 of papain ${ }^{2.3}$ rather than to the catalytic site Cys 25 (ref. 1), for which the analogous residue is Ser 588, prompted Mottram et al. to suggest ${ }^{3}$ that the $111 \mathrm{~K}$ antigen might represent an evolutionary intermediate between cysteine and serine proteinases.

In considering the possibilities for variation in the catalytic-site regions of cysteine proteinases and structurally related proteins, our isolation of a protein in a metastable configuration from the latex of Carica papaya in which first, the sulphur atom of Cys 25 probably exists as a disulphide with the sulphur atom of either Cys 22 or Cys 63 ; and second, one or other of these residues contains a free thiol group, may be of interest.

In papain, the side chains of Cys 25 and
His 159 form an interactive system with nucleophilic character in weakly acidic solution modulated by binding interactions and electrostatic field effects ${ }^{4.5}$. The $-\mathrm{S}^{-} /-\mathrm{Im}^{+} \mathrm{H}$ ion-pair component of this interactive system is probably the catalytic device responsible for the nucleophilic and general acid attack on the scissile bond of a substrate ${ }^{6}$. The side chains of Cys 22 and Cys 63 form one of the three disulphide bonds of the papain molecule, and analogous features are known to exist in other cysteine proteinases.

The reactivity of the thiol group of Cys 25 in active papain towards the twohydronic-state reactivity probe ${ }^{7} 2,2^{\prime}$ dipyridyl disulphide (2-Py-S-S-2-Py) is abnormally high in acidic media and maximal at $\mathrm{pH}$ 3.8. The abnormal reactivity derives from the coexistence at $\mathrm{pH} 3-4$ of significant concentrations of (Cys 25) $-\mathrm{S}^{-} /($His 159$)-\mathrm{Im}^{+} \mathrm{H}$ ion pair and the highly electrophilic 2-Py-S-S-2$\mathrm{Py}^{+} \mathrm{H}$ cation ${ }^{6}$.

In marked contrast, the thiol group of the metastable papaya latex protein ('propapain') exhibits more normal reactivity characteristics typical of a 'bare' thiol group that is not part of a Cys-His interactive system, with maximal reactivity in alkaline media and negligible reactivity in acidic media ${ }^{8.9}$. Treatment with a low molecular mass mercaptan such as cysteine converts the inactive, thiol-containing, metastable protein into catalytically active papain, with retention of thiol stoichiometry and with marked change in thiol reactivity characteristics to those typical of cysteine proteinase catalytic sites ${ }^{6}$.

The results of kinetic $^{*}$ and labelling ${ }^{9}$ experiments support the view that the metastable protein is a structural isomer of papain containing a different disulphide bond (Cys 22-Cys 25 or Cys 25-Cys 63), and that its conversion to papain involves thiol-promoted thiol-disulphide interchange to produce the free thiol group of Cys 25, which forms the catalytic-site ion pair with His 159 .

KEITH BROCKLEHURST

\section{Department of Biochemistry,}

St Bartholomew's Hospital Medical College,

University of London,

Charterhouse Square,

London EC1M 6BQ, UK

1. Higgins, D.G., McConnell, D.J. \& Sharp, P.M. Nature 340, 604 (1989)

2. Eakin, A.E., Higaki, J.N., McKerrow, J.H. \& Craik, C.S Nature 342, 132 (1989).

3. Mottram, J.C., Coombs, G.H. \& North, M.J. Nature 342, 132 (1989).

4. Brocklehurst, K et al. Biochem. J. 256, 543-555 (1988).

5. Kowlessur, D. et al. Biochem. J. 259, 443-452 (1989).

6. Brocklehurst, K., Willenbrock, F. \& Salih, E. in Hydrolytic Enzymes (eds Neurberger, A. \& Brocklehurst, K.) 39-158 (Elsevier, Amsterdam, 1987).

7. Brocklehurst, K. Meth. Enzym. 87C. 427.-469 (1982).

8. Brockiehurst, K. \& Kierstan, M.P.J. Nature new Bio!. 242, 167-170 (1973).

9. Kierstan, M.P.J., Baines, B.S. \& Brocklehurst, K. Biochem. Soc. Trans. 10, 172-173 (1982). 